\title{
PENANGANAN ANESTRUS PASCA BERANAK SAPI PERAH DENGAN IMPLAN PROGESTERONE INTRAVAGINA DI KELOMPOK TANI TERNAK KECAMATAN NGABLAK KABUPATEN MAGELANG
}

\author{
Supriyanto ${ }^{1}$ \\ 1) Jurusan Penyuluhan Peternakan, STPP Magelang \\ J1. Magelang-Kopeng Km 7 Purwosari, Tegalrejo, Magelang \\ E-mail: stppsupriyanto@gmail.com
}

Diterima: 24 Agustus $2016 \quad$ Disetujui: 08 November 2016

\begin{abstract}
ABSTRAK
Upaya untuk meningkatkan populasi sapi perah dengan salah satu teknologi inseminasi buatan banyak kendala, salah satunya adalah sulitnya deteksi estrus, karena kejadian anestrus sangat umum pada sapi perah setelah lahir. Tujuan dari penelitian ini menggunakan teknik sinkronisasi estrus menggunakan intravaginal implan progeterone untuk mengatasi anestrus di sapi perah pasca melahirkan. Duapuluh ekor sapi perah blasteran yang dimiliki oleh Kelompok Tani ternak di Kabupaten Kabupaten Magelang desa Ngablak dibagi menjadi dua kelompok perlakuan. pengobatan menggunakan implan progesteron CIDR selama 10 hari di intravaginal, II sebagai pengobatan untuk kontrol menggunakan implan kosong selama 10 hari untuk intravaginal sebagai kontrol. Pengamatan birahi dilakukan setelah pengambilan implan dan inseminasi buatan (AI) dilakukan setelah ternak menunjukkan gejala birahi. sapi perah menunjukkan ada tandatanda dari birahi lebih dari 3 periode estrus melakukan pemeriksaan ginekologi untuk menentukan status reproduksi dan kebuntingannya. Hasil menunjukkan kekuatan retensi intravaginal implan dianggap sempurna (100\%), induksi estrus menunjukkan perbedaan awal $(66,27 \pm 07.12$ vs $453,76 \pm 79,50 ; \mathrm{P}<0,01)$, jumlah sapi perah birahi adalah acara yang berbeda secara signifikan lebih tinggi $(100 \%$ vs $60 \%, \mathrm{P}<0,01)$, tingkat konsepsi $(\mathrm{CR})$ yang dihasilkan tidak berbeda secara signifikan ( $80 \%$ berbanding 76,67\%), S / C tidak berbeda nyata $(1,43$ vs 1,57$)$, angka NR tidak berbeda secara signifikan $(73,33 \%$ berbanding $75 \%)$, estrus panjang siklus tidak berbeda secara signifikan $(19 \pm 2,23$ vs $19,5 \pm 0,67)$, angka kehamilan (PR) menunjukkan tidak ada perbedaan yang lebih tinggi $(95,50 \%$ berbanding $57,67 \%, \mathrm{P}<0,01)$, jumlah sapi bunting secara signifikan berbeda $(93,33 \%$ berbanding $46,67 \%, \mathrm{P}<0,01)$. Dapat disimpulkan bahwa teknik sinkronisasi dengan progesteron intravaginal mampu menangani anestrus sapi perah setelah lahir.
\end{abstract}

Kata kunci: anestrus, implan progesterone, intravaginal

HANDLING OF DAIRY CATTLE ANESTRUS POST BIRTH WITH INTRAVAGINAL PROGESTERONE IMPLANT IN THE DISTRICT LIVESTOCK FARMERS GROUP NGABLAK MAGELANG DISTRICT

\begin{abstract}
Efforts to increase the population of dairy cattle with one of the technologies that artificial insemination many obstacles, one of which is the difficulty of estrus detection, because the incidence of anestrus is very common in dairy cows after birth. The aim of this
\end{abstract}


study using estrus synchronization technique using intravaginal implant progeterone to overcome anestrus in cattle dairy cows post-birth. Some 20 head of crossbreed dairy cows owned by farmers group of cattle in the district of Magelang regency Ngablak village is divided into two treatment groups. The treatment I use imlan progesterone CIDR for 10 days in intravaginal, II as a treatment to control using an empty implant for 10 days for intravaginal as controls. Observations carried lust after implant retrieval and artificial insemination (AI) is made after cattle showed symptoms of lust. Dairy cows are showing no sign of lust over 3 periods of estrus do a gynecological examination to determine reproductive status and kebuntingannya. The results showed intravaginal retention power of the implant is considered perfect (100\%), induction of estrus showed a difference early (66.27 \pm 07.12 versus $453.76 \pm 79.50 ; P<0.01)$, the number of dairy cows lust is a different show significantly higher $(100 \%$ vs $60 \%, P<0.01)$, conception rate $(C R)$ generated is not significantly different (80\% versus $76.67 \%)$, the $S$ / C was not significantly different (1.43 versus 1.57), NR figures are not significantly different (73.33\% versus $75 \%)$, estrous cycle length was not significantly different $(19 \pm 2.23$ versus $19.5 \pm 0.67)$, pregnancy rate $(P R)$ showed no difference higher $(95.50 \%$ versus $57.67 \%, P<0.01)$, number of cows pregnant significantly different (93.33\% versus $46.67 \%, P<0.01)$. It can be concluded that the technique synchronization with intravaginal progesterone is capable of handling anestrus Dairy cows after birth.

Keywords: anestrus, progesterone implants, intravaginal

\section{PENDAHULUAN}

Usaha peternakan di indonesia sampai saat ini masih menghadapai banyak kendala yang mengakibatkan produktivitas ternak masih rendah, ini dibuktikan dengan rendahnya perkembangan populasi ternak sampai dengan pada tahun terahkir ini. Badan Statistik Nasional menyatakan bahwa dalam kurrun waktu 2008 sampai dengan 2012 kenaikan rata-rata populasi ternak adalah sebagai berikut: sapi potong $7,80 \%$, sapi perah 5,52\%, kerbau 10,19\%, kuda 6,84\%, kambing 5,66 \%, domba $13,81 \%$ dan babi $4,98 \%$, angka perkembangan tersebut tidak sesuai dengan meningkatnya permintaan masyarakat akan produk-produk peternakan sebagai bahan makanan yang bergizi tinggi.

Daerah kabupaten Magelang rata-rata kidding interval pada sapi perah lebih dari 12 bulan, jarak beranak yang panjang merupakan dampak anestrus pasca beranak atau gangguan lain, disamping itu adanya birahi yang tidak teramati yang merupakan hal yang umum dijumpai pada Sapi perah pasca beranak (Sutama et al., 1995).

Kinerja Reproduksi Sapi perah merupakan suatu proses yang kompleks dan dapat terganggu pada berbagai stadium sebelum dan sesudah permulaan siklus reproduksinya. Hewan betina harus menghasilkan ovum yang hidup dan diovulasikan pada waktu yang tepat, harus memperlihatkan birahi dekat waktu ovulasi sehinggga kemungkinan terjadi fertilisasi dapat dipertingggi. Usaha ternak Sapi perah di tingkat petani dengan demikian perlu memperhatikan penampilan reproduksinya, hal ini penting untuk menjamin kelangsungan produktivitas yang tinggi baik susu maupun anaknya (Utomo, 2011).

Tehnik Sinkronisasi adalah salah satu cara mengatasi ternak ruminansia yang mempunyai performan reproduksi rendah, tehnik ada 2 cara yaitu dengan melisiskan korpus luteum dan kedua dengan substitusi 
fungsi korpus luteum. Lisisnya korpus luteum akan diikuti dengan pembebasan gonadotropin yang menyebabkan timbulnya birahi, perkembangan folikel, ovulasi dan pembentukan korpus luteum (Peter, 1986). Substitusi korpus luteum dengan pemberian hormon progesterone eksogen akan menyebabkan penekanan pembebasan hormon gonadotropin dengan tiba-tiba, yang berakibat terjadinya perkembangan folikel, timbulnya gejala birahi dan ovulasi secara serentak (Suharto et al., 2008 dan Putro, 2013).

Senyawa progesterone mempunyai beberapa keunggulan untuk sinkronisasi dibanding dengan prostaglandin, antara lain mampu meningkatkan ferlititas, dapat digunakan pada hewan mengalami inaktivitas ovarium (Cavalieri et al., 2007). Hormon progesterone yang dimasukkan secara intravagina merupakan agen sinkronisasi intravagina selama 9-15 hari menghasikan angka konsepsi 58\% -66\% pada sapi perah (Putro, 1991), sedangkan innersi selama selama 9 hari menyebabkan kenaikan progesteron plasma dan pencabutan implan setelah 9 hari menimbulkan penurunan progesteron tibatiba, memacu perkembangan folikel ovulasi, diikuti estrus dan ovulasi (Putro, 2013)

Dengan demkian bila kejadian estrus pertama pasca beranak yang panjang dapat ditangani atau dapat diperpendek waktunya, maka selang beranak dapat pula diperpendek waktunya dengan demikian terjadinya kebuntingan tidak tertunda, sebagai akibatnya kerugian petani peternak berupa biaya pemeliharaan secara ekonomi dapat ditekan selanjutnya dapat meningkatkan pendapatan petani peternak tersebut.

Bertitik tolak hal tersebut diatas maka akan dilakukan suatu penelitian pengaruh pemberian impalan progesterone guna menginduksi birahi dan ovulasi sehingga cepatnya dapat dikawinkan dan bunting.

\section{MATERI DAN METODE}

Bahan dan Alat Penelitian.

Penelitian dilakukan pada ternak kambing laboratorium ternak kecil Sekolah Tinggi Penyuluhan Pertanian Magelang dan Kelompok Tani Desa Glagahombo Kecamatan Tegalrejo dengan mengunakan: 1. Sapi perah pasca beranak sebanyak 20 ekor, pernah beranak, umur $\leq 3$ tahun, 7 bulan setelah beranak, mempunyai berat badan $\leq 400 \mathrm{~kg}$, belum pernah menunjukkan gejala birahi dan tidak mempunyai riwayat gangguan reproduksi; 2. Implan Hormon Progesteron terbuat dari spon berbentuk lingkaran diameter $3 \mathrm{~cm}$ panjang $5 \mathrm{~cm}$ dengan panjang tali $20 \mathrm{~cm}$, berisi Depo Progestin (medroxyprogesterone acetate) $60 \mathrm{mg}$ produksi Harsen Jakarta Indonesia; 3. Kemekalia antiseptik acriflafin dan vaselin; 4. Satu unit vaginoskop.

Jalannya Penelitian. Sapi perah perlakuan terbagi dalam pasangan (total 10 pasang) dalam tiap pasangan keadaan ternak dan umur ternak hampir sama, milik satu peternak atau peternak yang berdekatan dan mendapat perlakuan pemeliharaan yang relatif sama. Tiap pasangan mendapat perlakuan dengan mengunakan implan progesterone (Kelompok I) dan implan kosong (Kelompok II) intra vagina selama 12 hari. Tempat deposisi implan dalam vagina di depan servik, cara pemasangan implan dengan alat khusus (vaginoskop) sebelumnya di sterilisasi dengan acriflavin demikian juga dengan alat kelamin ternak perlakuan. Data yang didapat dianalisa dengan statistik uji-square dan uji-t (Snedecor dan Cochran, 1980). 
Pengamatan birahi. Setelah 12 hari implan dilepas kemudian dilakukan pengamatan birahi empat kali dalam sehari, perkawinan dilakukan dengan pejantan.

Pemeriksaan

kebuntingan.

Pengamatan intensif setelah 18 hari setelah perkawinan sampai dengan terjadinya kelahiran.

Variabel yang diamati. Variabel yang diamati adalah daya retensi intravagina, induksi birahi, angka konsepsi (CR) dan angka kebuntingan (PR). Sebagai data pendukung adalah data $\mathrm{S} / \mathrm{C}$, angka NR, panjang siklus estrus dan jumlah sapi bunting.

\section{HASIL DAN PEMBAHASAN}

\section{Daya Retensi Intravagina}

Implan CIDR yang terpasang sebanyak 20 buah (10 pasang sapi $\mathrm{PFH}$ ) yang diinsersikan kedalam vagina mepunyai daya retensi sebesar $100 \%$ ( tidak satupun implan yang lepas). Hasil daya retensi yang sempurna tersebut dimungkinkan karena bentuk dari karet silikon yang elastik bahkan pada sapi yang longggar vaginanya, hasil daya retensi yang sempurna juga dilaporkan oleh Supriyanto (2000), Supriyanto (2006) bahwa selama melakukan penelitian dengan mengunakan CIDR yang diinsersikan pada sapi laktasi yang berbeda tidak lepas. Putro (2013) melaporkan karena bentuk CIDR yang menyerupai huruf $\mathrm{T}$ sehingga memberikan kemampuan retensi intravagina yang sempurna, dengan vagina yang sudah longgar tidak dijumpai terjadinya implan CIDR yang lepas sebelum diambil.

\section{Induksi Birahi}

Hasil pengolahan data sapi perah pada terjadinya berahi Kelompok I menunjukkan adanya perbedaan lebih awal
$(66,27 \pm 07,12 \quad$ versus $\quad 453,76 \pm 79,50$; $\mathrm{P}<0,01)$ dari pada Kelompok II, jumlah Sapi perah yang menunjukkan birahi adalah berbeda nyata lebih tinggi (100\% vs $60 \%$, $\mathrm{P}<0,01)$.

Sapi perah pada kelompok perlakuan I menunjukkan gejala birahi dalam waktu rata-rata $(66,27 \pm 07,12)$ jam setelah pengambilan implan, dengan angka birahi 100\% (sebanyak 10 ekor), sedangkan pada kelompok II birahi ditunjukkan dengan waktu rata-rata $(453,76 \pm 79,50)$ jam setelah pengambilan implan dengan angka birahi sebesar 60\% (6 ekor). Hasil birahi dan waktu birahi pada masing-masing kelompok perlakuan dengan analisa statistik terdapat perbedaan yang sangat nyata pada kelompok perlakuan I dengan II, baik pada jumlah sapi yang menunjukkan gejala birahi dan jarak antara pengambilan implan sampai timbulnya birahi $(\mathrm{P}<0,01)$.

Tehnik induksi birahi pada sapi perah pasca beranak dengan menggunakan implan progesterone memberikan hasil yang memuaskan, dengan terjadinya birahi pada semua sapi pada kelompok I sebesar $100 \%$. Rendahnya persentase induksi birahi sapi pada kelompok II sebesar 60\%, menunjukkan bahwa anestrus pasca beranak merupakan hal yang umum dijumpai pada sapi perah, dengan demikian implan progesterone berhasil mengatasi masalah anestrus pada kambing pasca beranak dengan terinduksinya birahi lebih awal pada semua Sapi perah perlakuan I dalam waktu $(66,27 \pm 07,12)$ jam setelah pengambilan implan dibanding dengan kambing kelompok II iyang membutuhkan waktu $(453,76 \pm 79,50)$ jam.

Hasil induksi birahi yang sempurna ini sesuai dengan hasil beberapa penelitian sebelumnya, antara lain dilaporkan oleh Wenkoff (1986) pemberian progesteron eksogen akan menyebabkan penekanan 
pembebasan hormon gonadotropin dari pituitaria anterior, penghentian pemberian progestron eksogen ini akan diikuti dengan pembebasan hormon gonadotropin secara tiba-tiba, yang berakibat terjadinya birahi dan ovulasi secara serentak dalam waktu 23 hari setelah penghentian. Putro (1991) pemberian progesteron pada sapi subsestrus maupun anestrus selama 15 hari yang diinersikan secara intravagina mampu menginduksi birahi dan ovulasi dengan selang waktu antara 2-4 hari.

Anderson dan Macmillan (1994) dan Ryan et al. (1995) melaporkan tehnik sinkronisasi dengan cara substitusi fungsi korpus luteum dengan menggunakan implan progesteron secara intravagina 7-15 hari menyebabkan penekanan pembebasan hormon gonadotropin. Pengambilan implan akan menghasilkan pembebasan hormon gonadotropin dengan tiba-tiba yang berakibat terjadinya perkembangan folikel, timbulnya gejala birahi dan ovulasi secara serentak

Kresno dan Eko (2010) hasil penelitiannya bahwa pengaruh sinkronisasi estrus dengan menggunakan Implant Intravagina Controlled Internal Drug Release (CIDR), waktu pertama kali munculnya estrus dengan onset estrus 23,50 jam pada respon estrus $\pm 26,55$ jam dan durasi estrus 35,61 jam. Disarankan penggunaan CIDR selama 10 hari dapat digunakan untuk sinkronisasi estrus dengan respon $100 \%$, perlunya pembuatan CIDR dari dalam vagina sehingga biaya sinkronisasi bisa ditekan, perlunya sosialisasi penggunaan CIDR dalam sinkronisasi estrus

Putro (2013) menyatakan estrus terjadi $66,18 \pm 03,42 \quad$ jam setelah pengambilan implan. Insersi CIDR menyebabkan hambatan perkembangan folikel dominan, namun setelah pengambilan implan perkembangan folikel ovulasi terjadi sangat pesat, mencapai ukuran maksimum dan ovulasi pada hari berikutnya. Implan CIDR juga menyebabkan regresi korpus luteum. Peningkatan kadar progesteron plasma terjadi setelah insersi CIDR dan terjadi penurunan dengan tiba-tiba setelah pencabutan implan, hingga kurang dari 0,50 $\mathrm{mg} / \mathrm{ml}$ dalam waktu 3 hari saat timbul gejala estrus. Implan CIDR merupakan progestin poten untuk sinkronisasi estrus. Insersinya menyebabkan kenaikan progesteron plasma dan pencabutan implan setelah 9 hari menimbulkan penurunan progesteron tiba-tiba, memacu perkembangan folikel ovulasi, diikuti estrus dan ovulasi. Insersi implan ini juga menghambat perkembangan korpus luteum, sehingga pemberian PGF2a tidak berdampak pada penurunan kadar progesteron plasma.

\section{Angka Konsepsi (CR)}

Angka konsepsi yang dihasilkan tidak berbeda nyata $(80 \%$ vs $76,67 \%$ ) hal ini menunujukkanbahwa tingkat fertilitas hewan yang berahi terinduksi progesteroneCIDR tidak berbeda dengan fertilitas hewan berahi alami. Angka konsepsi cukup tinggi baik pada kelompok perlakukan maupun kontrol. Dilihat dari persentase angka kebuntingan, maka perlakuan progesteron yang merupakan metode yang cukup efektif dalam upaya peningkatan angka kebuntingan, sehingga dapat memperbaiki efisiensi reproduksi sapi perah anestrus.

Hasil tersebut lebih tinggi dibandingkan dengan hasil hasil penelitian yang dilakukan oleh Supriyanto (2000) angka konsepsi yang didapat adalah $75 \%$ ( $6 / 8$ ekor) dan 73,33\% (11/15 ekor), selanjutnya Solihati (2008) hasil penelitian menunjukkan, bahwa perlakuan 
progesteron menghasilkan angka kebuntingan (71,4\%). Hastuti (2008) dari hasil penelitiaannya diperoleh hasil bahwa angka konsepsi cukup yaitu 63,55 persen terhadap para petani peternak sapi potong yang berada di kecamatan Petanahan, Puring dan Ayah kabupaten Kebumen.

Angka konsepsi yang didapatkan pada penelitian ini sedikit lebih tinggi, ini menunujukkan bahwa sinkrosisasi dengan menggunakan CIDR-progesteron sapi perah paska beranak berhasil dengan baik, dengan demikian bahwa CIDR-progesterone dapat mengatasi masalah yang umumnya terjadi pada sinkronisasi birahi dengan preparat lain yang umumnya angka konsepsi lebih rendah.

Arifiantini et al. (2010) menyatakan bahwa, angka konsepsi ditentukan oleh 3 faktor yaitu kesuburan pejantan, kesuburan betina dan teknik inseminasi. Pada perkawinan normal jarang ditemukan suatu keadaan dimana hewan jantan dan betina mencapai kapasitas kesuburan $100 \%$. Walaupun masing-masing mencapai tingkatan kesuburan $80 \%$, pengaruh kombinasinya menghasilkan angka konsepsi sebesar 64\% (80x80). Teknik inseminasi yang baik akan mempertahankan nilai ini, akan tetapi setiap penurunan efisiensi reproduksi merupakan suatu persamaan faktorial dari ketiga variable tersebut diatas (prosentase kesuburan jantan $\mathrm{x}$ prosentase kesuburan betina $\mathrm{x}$ prosentase efisiensi kerja inseminator) (Arifiantini et al., 2010).

Rendahnya CR hasil inseminasi dengan semen beku pada penelitian ini kemungkinan disebabkan oleh beberapa faktor, pertama terlambatnya waktu inseminasi, kedua kemungkinan kurangnya jumlah spermatozoa motil yang diinseminasikan. Menurut Katila (2005), saat ini konsentrasi spermatozoa yang digunakan untuk IB pada kuda antara 5 sampai dengan 500 x106. Semen beku yang digunakan pada percobaan ini mempunyai PTM antara 35\%-40\% dengan jumlah total spermatozoa motil dari semen beku yang diinseminasikan sebanyak 250 sampai dengan 300x106. Menurut Vidament et al. (2002), jumlah sel motil untuk IB menggunakan semen beku antara 150 sampai dengan 300x106, bahkan Woods et al. (2000), Morris et al. (2003) dan Siemme et al. (2004) melaporkan angka kebuntingan yang cukup tinggi dengan konsentrasi spermatozoa $<50 \times 106$, tetapi dalam penelitian ini meskipun dengan jumlah sel yang cukup tinggi, fertilisasi tidak terjadi.

\section{Angka Kebuntingan (PR)}

Hasil penelitian menunjukkan ada perbedaan lebih tinggi $(95,50 \%$ versus $57,67 \%, \mathrm{P}<0,01)$, untuk mendapatkan angka kebuntingan dilakukan pemeriksaan 2 kali dengan plapasi abdomen pada bulan ke 3 dan ke 5 setelah perkawinan dalam penelitian ini menunjukkan bahwa kelompok perlakuan I dengan kelompok II tidak ada perbedaan yang nyata $(\mathrm{P}>0,05)$.

Angka kebuntingan yang tinggi pada kelompok perlakuan I (90\% atau 9/10 ekor) dan II (83,33\% atau 5/6 ekor) menunjukkan bahwa perkawinan yang dilakukan tersebut berhasil tentunya tidak lepas dari akurasi deteksi estrus, saat perkawinan yang tepat dan tehnik perkawinan yang benar. Tingginya angka kebuntingan berhubungan dengan respon Positif terhadap pemberian implan progesteron sehinggga dapat merangsang aktivitas ovarium lebih baik sehingga penampakan birahi lebih cepat dan jumlah ternak yang bunting lebih banyak. Hal ini sesuai pendapat bahwa implan progesteron merupakan salah satu hormon yang dapat digunakan untuk 
mengatasi performen reproduksi yang rendah pada ternak kambing di peternak, progesteron dibuktikan dapat mengatasi masalah yang umumnya terjadi pada hormon-hormon/preparat lain seperti prostaglandin, untuk mengatasi kegagalan reproduksi antara lain masalah anovulasi, ovulasi tertunda maupun korpus luteum berumur pendek (Supriyanto, 2000 dan Putro, 2013).

Progesterone juga dapat digunakan untuk mensinkronisasi birahi, pengobatan pada ternak yang mengalami anestrus, dan untuk meningkatkan angka kebuntingan dan fertilitas (Xu et al., 1997 dan Pemayun et al., 2014), selanjutnya sinkronisasi estrus dengan porgesteron sintetik telah dirasakan hasil yang memuaskan, baik pada kelompok hewan domestik konvensional seperti kambing dan domba, maupun jenis lain seperti rusa (Muir et al., 1997 dan Nurcholidah, 2008).

Cara standar sinkronisasi birahi meliputi 2 kali penyuntikan prostaglandin dengan selang 10-12 hari. Birahi akan terjadi dalam waktu 72-96 jam setelah penyuntikan kedua. Pelaksanaan inseminasi dilakukan 12 jam setelah kelihatan birahi, atau sekali pada 80 jam setelah penyuntikan kedua. Sinkronisasi birahi dengan prostaglandin hanya akan berhasil pada kerbau yang bersiklus birahi normal dan tidak akan meningkatkan angka konsepsi melebihi inseminasi pada birahi alam. Angka konsepsi dari inseminasi pertama dengan sinkronisasi birahi ini tidak setinggi pada sapi, tetapi hanya berkisar antara 3040 (Sujarwo, 2009).

\section{SIMPULAN DAN SARAN}

\section{Simpulan}

Teknik sinkronisasi birahi dengan menggunakan implan progesteron intravagina pada sapi perah pasca beranak mampu menginduksi birahi dan ovulasi, serta mengatasi problem anestrus sehingga mampu mengoptimalisasi hasil perkawinan dan meningkatkan efisiensi reproduksinya.

\section{Saran}

Untuk mengoptimalisasi hasil perkawinan dan meningkatkan efisiensi reproduksi, maka teknik sinkronisasi birahi dengan progresteron intravagina dapat digunakan.

\section{DAFTAR PUSTAKA}

Arifiantini, R. I., B. Purwantara, T. L. Yusuf, D. Sajuthi, dan Amrozi, 2010. Angka Konsepsi Hasil Inseminasi Semen Cair Versus Semen Beku pada Kuda yang Disinkronisasi Estrus dan Ovulasi. Media Peternakan. Vol. 33 No.1. Pp. 1-5Anderson, L.H. and Mac Day., 1994. Acute Progesterone Administration Regresses Persitent Dominant and Improves Fertility of Cattle in Ehich Estrus was Synchronized with Melengestrol Actate. J. Anim. Sci. 72:2955-2961.

Cavalieri, J., G. Hepworrth, V. M. Smart, M. Ryan and K. L. Macmillan., 2007. Reproductive performance of lactating dairy cows and heifers synchronized for a second inseminasi with an intravaginal progesterone-releasing device 7 or 8 $\mathrm{d}$ with estradiol benzoate injected at the time of device insertion and $24 \mathrm{~h}$ after removal. Theriogenology 64 :824-834.

Hastuti, D. 2008. Tingkat Keberhasilan Inseminasi Buatan Sapi Potong Di Tinjau Dari Angka Konsepsi Dan 
Service Per Conception. Mediagro . Vol. 4. No.1. Pp. 2-20

Kresno S. dan Eko M. 2010. Sinkronisasi Estrus Dengan Implant Controlled Internal Drug Release Intravagina Pada Kambing Peranakan Ettawa. Buana Sains. Vol 10 No 1: Pp. 1-7

Muir, P. D., G. Semiadi, G.W. Aser, T. E. Broad, M. L. Tate and T.N. Barry., 1997. Sambar deer (Cervus unicolor) X Red deeer (C. elephus) interspecies hybrids. Jurnal of Heredity 88: 366-372.

Nurcholidah, S., 2008. Penggunaan Progesteron Intravaginal Dan Kombinasinya Dengan Pgf2 $\alpha$ Serta Estrogen Dalam Upaya Menimbulkan Estrus Dan Kebuntingan Pada Sapi Perah Anestrus. Jurnal Bionatura, Vol. 10, No. 3, Pp 258-272.

Pemayun, T.G.O., I.G.N.B.Trilaksana., M.K.Budiasa., 2014. Waktu Inseminasi Buatan yang Tepat pada Sapi Bali dan Kadar Progesteron pada Sapi Bunting. Jurnal Veteriner . Vol. 15 No. 3 : 425-430

Peter, A.R., 1986. Hormonal control of the bovine oestrous cycle. BR. Veteriner J. 142 : 564-575.

Putro, P. P., 1991. The treatment of Anaoestrous and Suboeestrous in Dairy Cattle Using ProgesteroneControlled Internal Drug Release (CIDR) or a Sinthetic Gonadotrophin Release Hormone (GnRH). Buletin FKH-UGM. Desember ed.

Putro, P.P., 2013. Dinamika folikel ovulasi setelah perlakuan sinkronisasi estrus dengan implan progesteron intravagina pada sapi perah. Jurnal Sain Vet. 31 (2) : 128-137.

Ryan, P.P., S. Spiner, H. Yaakup And K.J. O Ferrell, 1995. An Evaluation of Estrous Synchronization Programs in Reproductive Management of Dairy Herds. J.Anim Sci. 73:3693695.

Siregar, T.N., H. Hamdan, G. Riady, B. Panjaitan, D. Aliza, E. F. Pratiwi, T. Darianto and Husnurrizal., 2014. Efficacy of two estrus synchronization methods in indonesian aceh cattle. Inter J. Vet. Sci., 4(2): 87-91. www.ijvets.com

Snedecor, G.W. and Cochran, W.G., 1990. Statistic Methods. 7th. RD. Iowa University Press. Ames. Iowa. USA.

Suharto, K., A. Junaidi, A. Kusumawati, D.T. Widayati, 2008. Perbandingan Fertilitas antara Sapi perah Peranakan Etawa Skor Kondisi Tubuh (SKT) Kurus versus Ideal Setelah Sinkronisasi Estrus dan Inseminasi buatan. FKH UGM. Media Kedokteran Hewan. 24: 4954.

Sujarwo, S., 2009. Penerapan Tehnik Sinkronisasi Birahi pada Kerbau dan Problemnya. Dinas Peternakan Sulawesi Selatan.

Supriyanto, 2000. Pengaruh Pemberian Suatu Implan Progesteron Intravagina terhadap induksi birahi, angka konsepsi dan kadar progesteron air susu sapi perah pasca beranak. Tesis. Program pasca sarjana UGM. Yogjakarta.

Supriyanto, 2014. Pengaruh pemberian Implan Progesteron Intravagian terhadap Induksi Berahi dan angka 
kebuntingan Kambing peranaka

Etawa (PE). J. Pengembangan

Penyuluhan Pertanian. Vol. 10. No.

20. Pp.221-226

Sutama, I.K., I.G.M. Budiarsana and Y. Saefudin., 1995. Kinerja reproduksi sekitar pubertas dan beranak pertama Sapi perahranakan etawah. Jurnal Ilmu dan Peternakan. 8 (1): 9-12.

Utomo, S., 2011. Porduktifitas Sapi perah di Wilayah Pengembangan Pesisir Pantai Kecamatan Wates, Kulon Progo. Laporan Penelitian. Universitas Mercu Buana Yogyakarta.

Wenkoff, M., $1986 . \quad$ Estrous Synchronisation in Cattle. Dalam Current Therapy in Theriology. Morror, DA.,(ed) WB., Saunders Co. Philadephia.

$\mathrm{Xu}$, Z. Z., L. J. Dorton and K. L. Macmillan, 1997. Reproductive Performance of Lactation Dairy Cows Following Estrous Synchronization Regimens with PGF $2 \alpha$ and progesteron. Theriognology. 47: 687-701. 